\title{
Safety Assessment of Ship Collision with Piers under the Protection of Anti-Collision Floating Box Based on BIM Technology
}

\author{
Ying-hao Chen $\mathbb{D}$, ${ }^{1,2}$ Cheng Liu, ${ }^{1,2}$ Xue-feng Zhao, ${ }^{1,2}$ and Fa-xiong $\mathrm{Li}^{1,2}$ \\ ${ }^{1}$ Research Institute of Highway, Ministry Transport, Beijing 10088, China \\ ${ }^{2}$ China-Road Transportation Verification \& Inspection Hi-Tech Co., Ltd., Ministry Transport, Beijing 10088, China
}

Correspondence should be addressed to Ying-hao Chen; chen.yh@rioh.cn

Received 20 August 2021; Revised 16 November 2021; Accepted 25 November 2021; Published 20 January 2022

Academic Editor: Jose Matos

Copyright ( $\odot 2022$ Ying-hao Chen et al. This is an open access article distributed under the Creative Commons Attribution License, which permits unrestricted use, distribution, and reproduction in any medium, provided the original work is properly cited.

\begin{abstract}
In order to research the force state of the piers subjected to a ship collision under the protection of floating anti-collision facilities, this study uses nonlinear spring connections to simulate the impact of ship damping and incidental water quality in the collision area. BIM technology is used to realize a safety evaluation method for the anti-collision floating box protection when the ship is colliding with piers. Established a BIM-based parametric preprocessing model for ships, piers, and anti-collision facilities, and opened the interface with ABAQUS longitudinally. After realizing the parameter adjustment of the BIM model, the visual parameter adjustment can be realized without destroying the boundary conditions, load conditions, and meshing. Taking a rigid frame bridge as an example, the most disadvantage position of the bridge pier under ship collision is determined by the parameterization method. At the same time, multi-condition analysis was carried out on the ship impacting the pier anti-collision floating box at different angles, different tonnages, and different speeds. Finally, the analysis results are traced back to the BIM model, achieving the unified integration of BIM model information and finite element analysis results and the purpose of visual analysis of any working conditions. The results show that the use of BIM parameterization technology to achieve linkage with the finite element preprocessing model can improve the efficiency of multi-condition sensitivity analysis and achieve the purpose of visual dynamic adjustment. The safety assessment analysis of the pier under the protection of the anti-collision pontoon on the pier under various working conditions shows that the anti-collision pontoon effectively reduces the hazard of the ship colliding with the pier, and the impact force gradually increases with the change from the oblique collision to the frontal collision. The peak impact force increases with the weight of the ship and shows a nonlinear relationship, such that the peak value of impact force increases with the speed increase, and the speed and the peak values of impact force show basically a linear relationship.
\end{abstract}

\section{Introduction}

In recent years, the transportation industry in China has developed rapidly. According to the "Thirteenth Five-Year" transportation plan, the railway mileage in China can be 150,000 kilometers and highways mileage can be 5 million kilometers by 2020 . For areas where rivers, lakes, and seas are widely distributed, bridges could be the main transport mode to cross the sea. In China, many large-span bridges have been built in the Yangtze River, the Yellow River, the Pearl River, and the sea. The design consideration of the navigation holes is in accordance with navigation requirements. However, the conflicts between navigable ships and bridges are still inevitable, the ship collision with bridge posed a serious threat to the crossing channel bridges. In recent decades, there have been more than 1000 bridge damage accidents in the world [1-5], and ship collision accidents also occur frequently in China. For example, more than 70 ship collision accidents have occurred in the Wuhan Yangtze River Bridge since the bridge completion, and the direct economic loss has exceeded 10 million. The ship collision accident in Guangdong Jiujiang Bridge caused $200 \mathrm{~m}$ collapse and 8 people died. In the Ningbo Jintang Bridge, both bridge and ship were severely damaged by ship 
collision and 4 people were lost in this accident [6]. Most of the above situations were caused by ships hitting bridge piers. It is important to set up reasonable anti-collision facilities for bridge substructures in navigation areas where accidents have occurred.

Some scholars did relevant research on the anti-ship collision device itself and its protective effect on bridge piers. Ehler [7] studied the performance of the X-core anti-collision belt structure under ship collision by means of numerical simulation and experimental verification. Wang [8] and Hai-qing [9], among others, have conducted a large number of simulations on the dynamic response process of the collision between a ship and a pier with anti-collision facilities, using penalty functions as contact conditions and focusing on detailed research on the performance of the anticollision facilities. Yu et al. [10], among others, developed the arched self-floating water-lifting anti-collision device and analyzed its structural force characteristics and the anticollision effect of the ship after a collision. It satisfies the performance requirements while reducing the difficulty of replacement and maintenance. Geng et al. [11] simplified the ship, anti-collision facility, and bridge pier into a double freedom quality-spring system ship, and the equivalent model was used for numerical simulation to analyze the relative stiffness of the anti-collision facility. The effects of the relative stiffness of the anti-collision facilities and the bow on the reduction rate of impact force and the overall compression rate of the anti-collision facilities are also analyzed. For the arc anti-collision device, Xi-qin et al. [12] conducted a safety assessment of the arc-shaped waterlifting anti-collision device by means of numerical simulation and experimental comparison verification. Hai-zheng et al. [13] and Jiang and Wei [14], among others, conducted research on the anti-collision performance of bridge piers with outsourcing anti-collision materials and proved the feasibility of the outsourcing material anti-collision scheme.

The traditional finite element analysis method is used in the existing researches, most researchers use the penalty function method of point-to-surface contact and use pointto-surface contact as the contact condition to do research. The shortcoming of this analysis method is that the impact force, impact acceleration, and velocity are oscillated [15-17]. Besides, the content focuses on the anti-collision structure mostly, the research on force state of the pier under the protection of the floating anti-collision facility is limited. In respect of the issues above, this study takes a rigid frame bridge pier and pontoon anti-collision structure as the research object, and uses BIM technology to establish a parametric preprocessing model and then to achieve visual sensitivity analysis. This study simulates the situation of ships contact protective facilities by the six springs in the middle. The spring deformation force in each direction represents the force generated by the collision in the corresponding direction. In this way, the resulting oscillation problem can be avoided. Finally, the safety assessment of the ship collision with piers could be achieved, and the safety assessment result could back to the BIM model and realize the combined application for the BIM model and the finite element analysis.

\section{Definition of Collision Contact Conditions}

The slice theory is commonly used in analyzing ship hydrodynamics, which is a numerical simulation method. This study employs the direct calculation method based on slice theory from the literature $[18,19]$. By calculating ship hydrodynamic force, the calculation results are directly attached to the BIM model and then transferred to the corresponding finite element pre-treatment model. The location of the collision contact point between the ship and the collision avoidance facility is called the collision point, supposing that deformations occur around the collision points. This study adds intermediate nodes between the ship and the collision avoidance facility model, using nonlinear spring connecting the intermediate nodes, and then simulated the ship's damping and effect of incidental water quality in the collision area.

The characteristic of nonlinear damping is that damping is related to contact deformation. When the contact deformation is zero, the contact force should also be zero. Based on the continuous contact force model proposed in literature [20], a damping model is built on nonlinear springs. This method fully considers that the deformation and contact force change with time in contact. The time history variation in contact collision can be simulated accurately.

In the model, both stiffness coefficient and damping coefficient are related to deformation, as shown in the following equation:

$$
f(\delta, \delta)= \begin{cases}K \delta^{n}+\mu \delta^{n} \dot{\delta}, & \delta>0, \\ 0, & \delta=0,\end{cases}
$$

where $f(\delta, \delta)$ is the contact force; $\delta$ is the contact deformation; $\delta$ is the contact speed; $K$ is the stiffness coefficient; $\mu$ is the damping coefficient; and $n$ is the stiffness index, which is related to the structure itself, measured by static tests on the contacting objects. The simpler structure shape can be obtained through theoretical derivation [21].

The restitution coefficient is defined as the ratio of the relative speeds of the normal phase before and after the collision, and the coefficient of restitution $e$ is defined as shown in the following equation:

$$
e_{1}=\frac{v_{1}}{v_{0}},
$$

where $v_{1}$ is the relative speed after the collision and $v_{0}$ is the relative speed before the collision.

The restitution coefficient characterizes the energy loss during the collision. When the restitution coefficient is 1 , it means a completely elastic collision without energy loss; when the restitution coefficient is 0 , it means that the kinetic energy of the colliding object is completely lost in the form of heat energy. The relationship between the energy loss $\Delta E$ and the restitution coefficient in the collision process is shown in the following equation:

$$
\Delta E=\frac{1}{2} m\left(v_{0}^{2}-v_{1}^{2}\right)=\frac{1}{2} m v_{0}^{2}\left(1-e^{2}\right) .
$$


According to the nonlinear damping model and the area of the "hysteresis loop," the damping work is shown in the following equation:

$$
W=2 \oint \mu \delta^{n} \dot{\delta} \mathrm{d} \delta=\frac{2 \mu}{3 k} m v_{0}^{3} .
$$

According to the conservation of energy, the relationship between energy loss and damping work in the collision process is shown in the following equation:

$$
W=\Delta E \text {. }
$$

The relationship between the stiffness coefficient of the nonlinear spring and the damping coefficient and the restitution coefficient is as follows:

$$
K=\frac{4 \mu v_{0}}{3\left(1-e^{2}\right)} \text {. }
$$

\section{Ship Collision Analysis Based on BIM}

\subsection{Establishment of Parameterized Pretreatment Model} Based on BIM. A rigid frame bridge is in navigable waters, and its piers are double-column thin-walled piers. The overall layout is shown in Figure 1. Considering the navigation requirements and the river's water level change, the floating box structure anti-collision facilities are used to protect the piers.

The highest navigable water level of the river area is $15.76 \mathrm{~m}$, the lowest navigable water level is $7.43 \mathrm{~m}$, and the highest design navigable water level is $18.06 \mathrm{~m}$. Under different water level conditions, the position of anti-collision facilities of buoyancy tanks is different. In consideration of the response of the pier under different ship collision angles, it is necessary to establish a corresponding operating condition model. In this study, BIM software is used as a preprocessing tool to establish a parametric model of ships and collision avoidance facilities as shown in Figure 2, and to open up the interface with ABAQUS vertically. BIM technology is used to achieve two-way communication between BIM model and finite element model. The technical route is shown in Figure 3.

3.2. Parameter Determination. For the steel shell of the protective pontoon, assume that the material is ideally plastic, the material does not harden, and the bilinear constitutive model can be used to simulate the nonlinearity of the steel, as shown in Figure 4. For pier C30 concrete, considering that the actual use process does not allow plastic deformation of the pier, only the elastic stage of the concrete can be considered. The material parameters of the anticollision pontoon steel shell Q345 steel and the bridge pier C30 concrete are shown in Table 1.

A hyperelastic material model is used to simulate the rubber chord material around the protective pontoon. This study uses an improved Mooney-Rivlin model, which uses the first-order polynomial strain-potential energy function to simulate the model. The corresponding parameters of the rubber material in ABAQUS are $\mathrm{C}_{10}=3.2 \mathrm{MPa}$, $\mathrm{C}_{01}=0.8 \mathrm{MPa}$, and $D 1=0$ (indicating that the material is incompressible). The density of rubber is $1500 \mathrm{~kg} / \mathrm{m}^{3}$.

3.3. Determine the Most Disadvantageous Position of the Pier. Under different water level conditions, the position of anticollision facilities of buoyancy tanks is different. When a ship collision occurs, the point of action on the pier is also different. To verify the most unfavorable position of the bridge pier under the impact of the ship collision, a ship of $1500 \mathrm{t}$ is hit head-on the pier in the navigation direction at a speed of $3 \mathrm{~m} / \mathrm{s}$. The water level checking ranges are from the lowest navigable water level of $7.43 \mathrm{~m}$ to the highest designed navigable water level of $18.06 \mathrm{~m}$. In consideration of the integer water level between 8 and $18 \mathrm{~m}$, according to the above BIM parameterization method, the different water level height parameters are quickly adjusted and calculation for 13 working conditions is conducted.

The stress curve of the most unfavorable position for bridge pier under ship collision fitted under each working condition is shown in Figure 5. The most adverse stress position occurs at the junction of the cushion cap and the pile foundation and there is no large tensile stress at the junction of the pier top and the main beam. Among them, the maximum tensile stress under the working condition of the lowest navigable water level of $7.43 \mathrm{~m}$ is $1.63 \mathrm{MPa}$. As the water level increases, the maximum tensile stress shows a decreasing trend, and the decreasing trend rate increases with the increase of the water level. The reason is that as the water level rises far away from the junction of the pier and abutment, the flexibility of the pier at the impact position increases. For the ship collision effect, more energy could be absorbed by the ship and the anti-collision device.

The maximum deformation curve of the bridge pier under ship collision fitted under each working condition is shown in Figure 6. The maximum deformation of the pier under each working condition has occurred at the impact point, and as the water level increased, the maximum deformation of the pier is increased from $1.625 \mathrm{~mm}$ at $7.43 \mathrm{~m}$ (the lowest navigable water level) to $1.765 \mathrm{~mm}$ at $18.06 \mathrm{~m}$ (the highest design navigable water level). Other than that, the deformation trend is not significant with the low water level, since the greater rigidity is near the pier and abutment joint. The deformation shows a linear growth trend with the water level increase.

3.4. Different Angle. In actual ship collision accidents, sailing ships may have multiple possibilities such as frontal collision and oblique collision. To verify the impact on bridge piers with different impact angles of ship collision, a $1500 \mathrm{t}$ ship is used to collide with the bridge pier and protective devices at a speed of $3 \mathrm{~m} / \mathrm{s}$. The scenarios are shown in Table 2.

For the ship hitting the bridge pier and protective devices at different angles, the impact velocity varying with time is shown in Figure 7. The ship impact velocity is not obvious at the timing of contact between the ship and the protective devices. As the impact depth increases, the velocity decays 


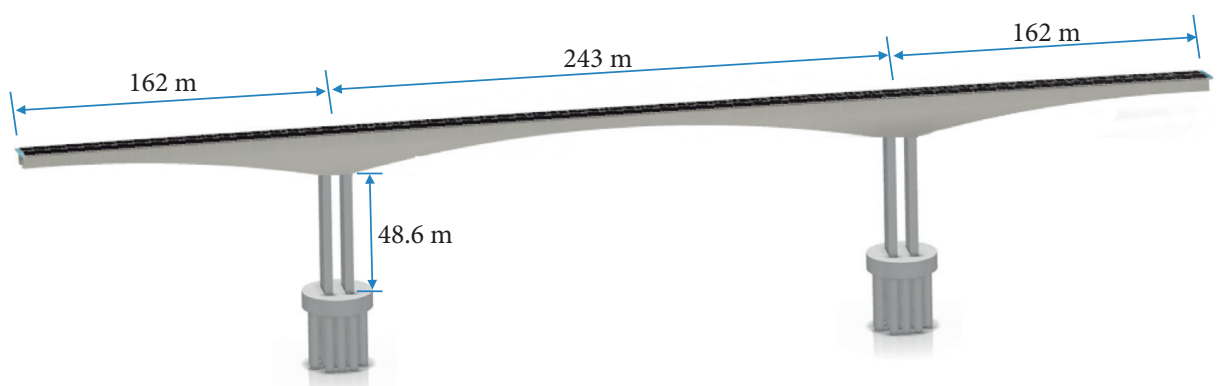

Figure 1: Three-dimensional layout of a rigid frame bridge.

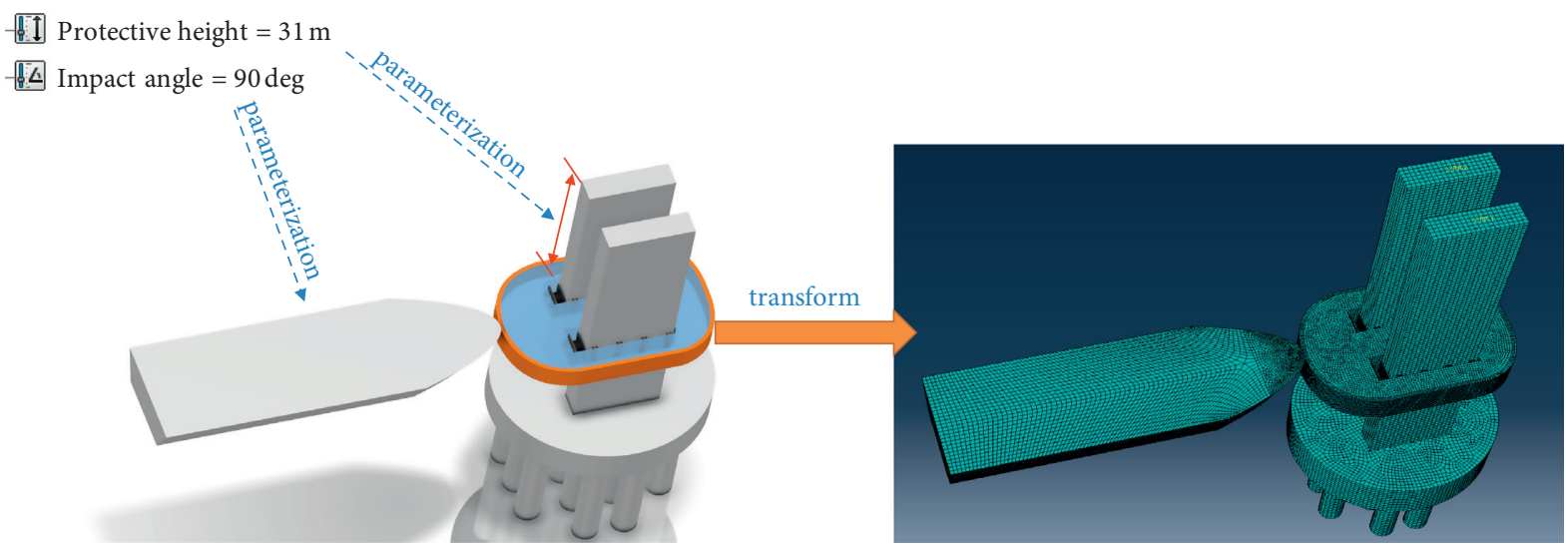

FIgURE 2: Schematic diagram of anti-collision facilities for ships and floating box.

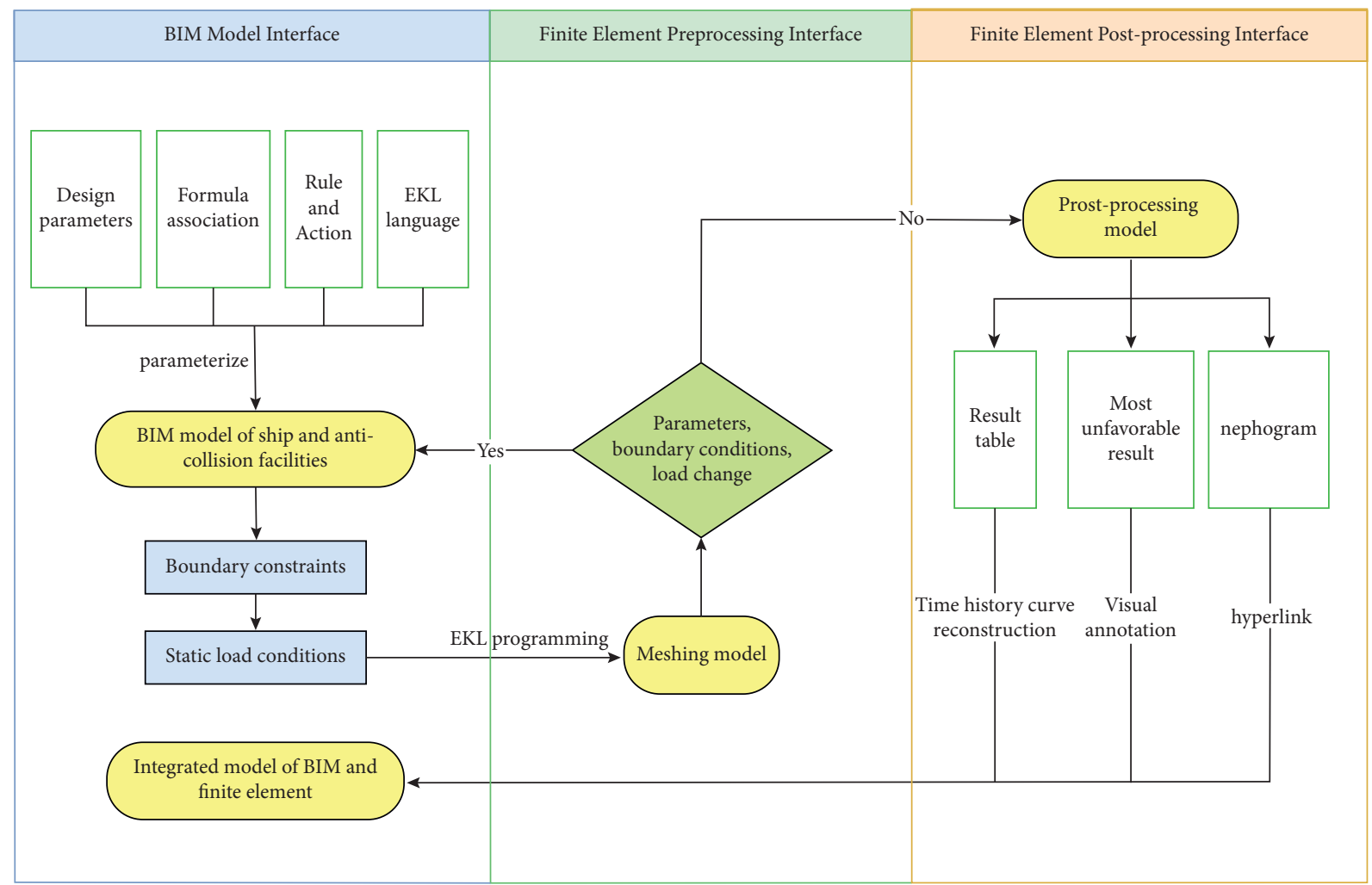

FIGURE 3: Technical roadmap of bidirectional communication between BIM model and finite element model of ship and buoyancy anticollision facility. 


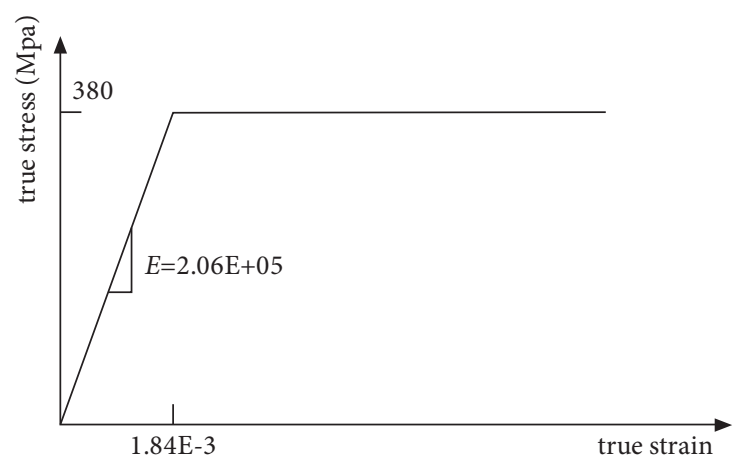

Figure 4: Steel stress-strain diagram.

TABLE 1: Material parameters of steel shell and pier.

\begin{tabular}{lccc}
\hline Material & Elasticity modulus $(\mathrm{MPa})$ & Unit weight $\left(\mathrm{kN} / \mathrm{m}^{3}\right)$ & Poisson's ratio \\
\hline Q345 steel & $2.06 E+05$ & 76.98 & 0.3 \\
C30 concrete & $3.00 E+04$ & 25 & 0.2 \\
\hline
\end{tabular}

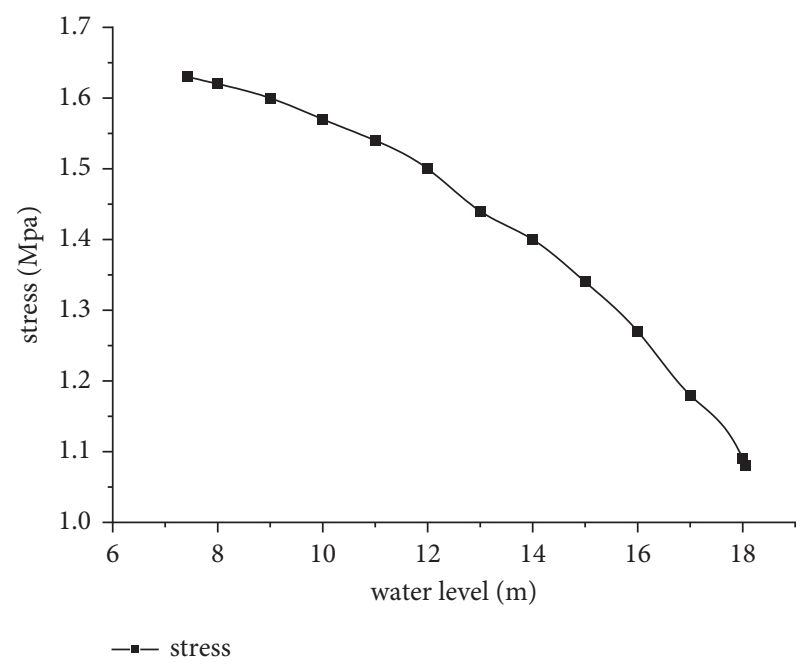

FIGURE 5: Stress curve of pier at the most disadvantage position under ship collision.

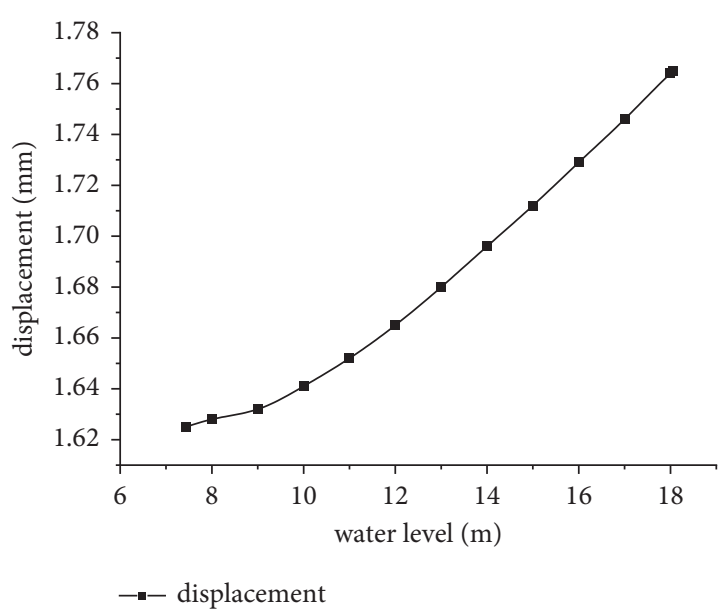

Figure 6: Maximum deformation curve of bridge pier under ship collision. rapidly, and the trend slows down when the velocity approaches zero. During a frontal impact, the velocity reduction response is faster than that of an oblique impact, and as the oblique collision angle increases, the velocity reduction response tends to be delayed.

Figure 8 shows the comparison of the impact force of the bridge piers with/without protective devices and ship collisions at different angles. Under the head-on collision condition 1 with protective devices, the impact force between the pier and the anti-collision device reached the maximum value of $9.78 \mathrm{MN}$ at around $1.5 \mathrm{~s}$. As a comparison, under the head-on collision condition 4 without protective devices, the impact force between the pier and the ship reached the maximum value of $34.24 \mathrm{MN}$ at around $0.05 \mathrm{~s}$. The maximum impact force in a frontal collision with protective devices was only 0.29 times the maximum impact force under the same conditions without anti-collision devices. For the same reason, Figure 7 shows that the maximum impact force of $6.4 \mathrm{MN}$ under the working condition 2 with a protective device with $60^{\circ}$ ship collision, which is 0.3 times the maximum impact force under working condition 5 without an anti-collision device under the same conditions. For $30^{\circ}$ ship collision effect, the maximum impact force under working condition 3 with a protective device is $4.3 \mathrm{MN}$, which is 0.37 times the maximum impact force under working condition 6 without an anti-collision device under the same situation. It could be seen that the anti-collision devices effectively reduce the hazard of the ship collision to the pier, and the impact force gradually increases with the oblique collision to the frontal collision. Besides that, the reduction effect of the protection devices on the collision force also increases gradually. This is mainly because under angular impact conditions, the role of drum dampers arranged in the orthogonal direction is weakened. Regarding the collision duration issue, the shorter duration of a non-protective device than a protective device is due to the rigid collision between the ship and the pier. 
TABLE 2: Impact scenarios at different angles.

\begin{tabular}{lcccc}
\hline Conditions & Impact angle $\left(^{\circ}\right)$ & Impact velocity $(\mathrm{m} / \mathrm{s})$ & Tonnage of ship $(\mathrm{t})$ & With anti-collision device or not \\
\hline 1 & 90 & 3 & 1500 & Yes \\
2 & 60 & 3 & 1500 & Yes \\
3 & 30 & 3 & 1500 & Yes \\
4 & 90 & 3 & 1500 & No \\
5 & 60 & 3 & 1500 & No \\
6 & 30 & 3 & 1500 & No \\
\hline
\end{tabular}

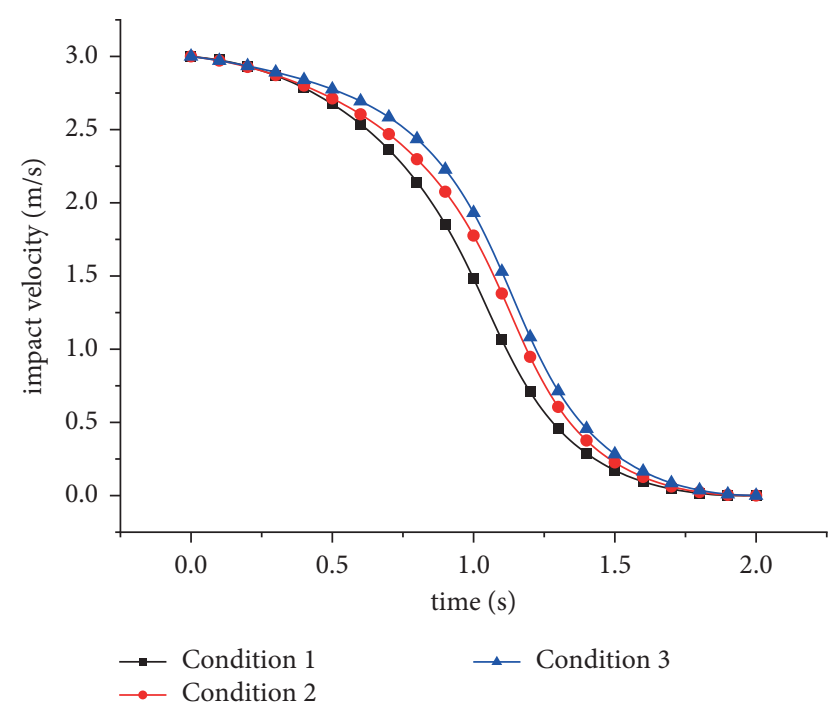

FIGURE 7: Velocity of impact varies with time at different angles.

3.5. Different Ship Tonnage. One of the main factors affecting the impact force of a ship is the tonnage. The mass of the ship can be changed by changing the material density of the rear end of the ship, which has little influence on the ship impact. For the purpose of verification of the different tonnage ships impact on the piers, assume the ship was kept heading towards the pier and the protective devices at $3 \mathrm{~m} / \mathrm{s}$ speed. The scenarios are shown in Table 3.

For ships of different tonnages colliding with piers with protective devices, the impact force changes over time are shown in Figure 9. Through comparison, for a $1000 \mathrm{t}$ ship, the impact force reaches a maximum of $9.18 \mathrm{MN}$ at around $1.51 \mathrm{~s}$; for a $1500 \mathrm{t}$ ship, the impact force reaches a maximum of $9.78 \mathrm{MN}$ at around $1.5 \mathrm{~s}$; and for a $2000 \mathrm{t}$ ship, the impact force is at $1.4 \mathrm{~s}$ reaches a maximum of $11.02 \mathrm{MN}$. The maximum impact force increases with the ship weight increase. However, it is not a linear relationship. The collision time increases with the increase of the ship's tonnage.

3.6. Different Impact Velocities. Another major factor affecting the impact force is the ship's speed. With respect to verifying the ship impact effects at different speeds on the bridge piers, a $1500 \mathrm{t}$ ship was used to impact the pier and the protective devices frontally at speeds of $3 \mathrm{~m} / \mathrm{s}, 4 \mathrm{~m} / \mathrm{s}$, and $5 \mathrm{~m} / \mathrm{s}$. The scenarios are shown in Table 4 .

For ships of different speeds hitting the piers with protective devices, the impact force changing over time is shown in Figure 10. Through comparison, the peak impact force increases with the increase of speed. When the ship speed is $3 \mathrm{~m} / \mathrm{s}, 4 \mathrm{~m} / \mathrm{s}$, and $5 \mathrm{~m} / \mathrm{s}$, the corresponding peak impact force is $9.78 \mathrm{MN}, 12.75 \mathrm{MN}$, and $16.12 \mathrm{MN}$, respectively. The ratio of the corresponding peak impact force is $1: 1.3: 1.65$, and the ratio of speed is $1: 1.33: 1.67$. As shown in Figure 11, the relationship between speed and peak impact force is basically linear. At the same time, it can be seen from Figure 10 that as the ship's speed increases, the time of the peak of the impact force moves forward, and when the ship's speed increases, especially for the $5 \mathrm{~m} / \mathrm{s}$ ship's speed, the time-history curve of the impact force curve fluctuates greatly. The reason is that as the speed of the ship increases, the collision force also increases, which resulting in an increase in the failure area of the bow and anti-collision devices, an increase in failure components, and thus the force situation was complicated.

3.7. Results Traceback BIM Model. According to the most adverse stress obtained from the calculation results, its parameters can be associated with the BIM model by means of table mapping, and the most unfavorable position under different working conditions can be viewed in the BIM model. As shown in Figure 12, for the time history calculation table under various working conditions, the time history can be redrawn and updated in the BIM software through the EKL language, and the time curve can be updated by adjusting the data sheet. Other calculation contents such as stress Cloud images are displayed in the hyperlinks form.

Through the above work, the purpose of BIM and finite element model parameterization preprocessing, model attribute information, and calculation result charts are linked to the unified model, to achieve the unified integration of multi-source BIM data and finite element analysis, visual analysis, and inspection under any working conditions.

3.8. Results and Discussion. Based on the above verification and discussion, the below items can be achieved by breaking through the interface between BIM modeling software and finite element analysis software:

(1) For the complex protection device constructed in this study, BIM software modeling can improve the efficiency. 


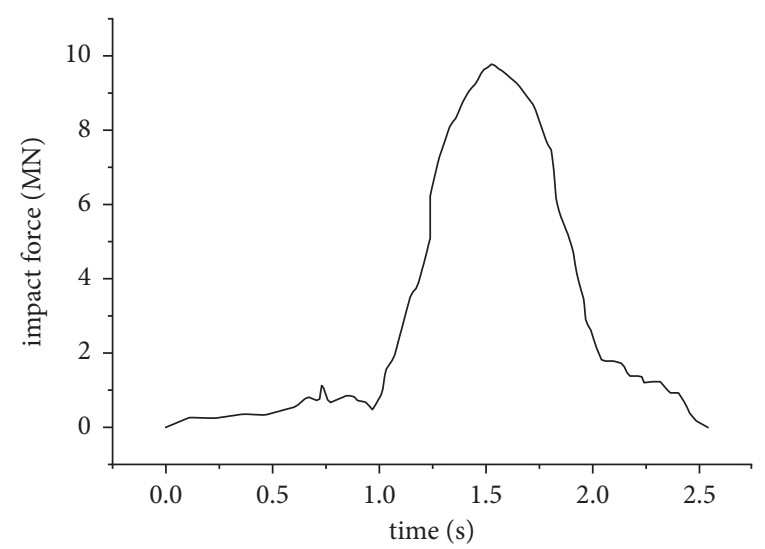

— Condition 1

(a)

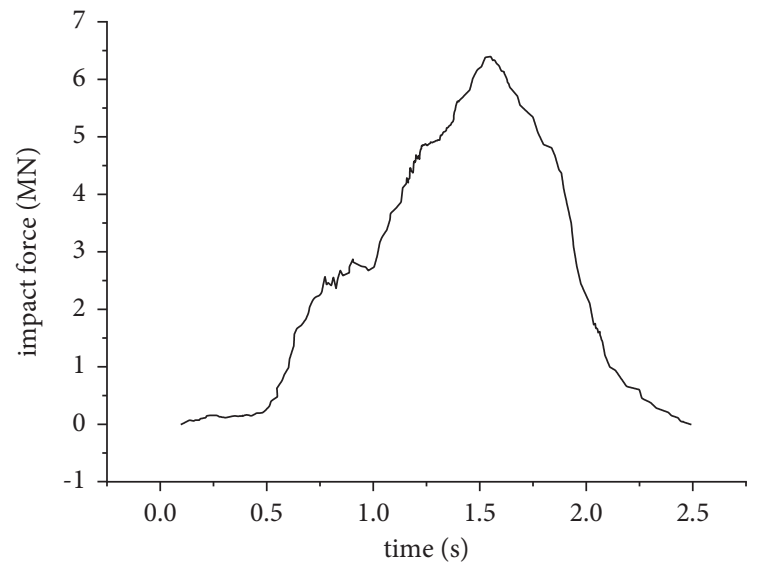

Condition 2

(c)

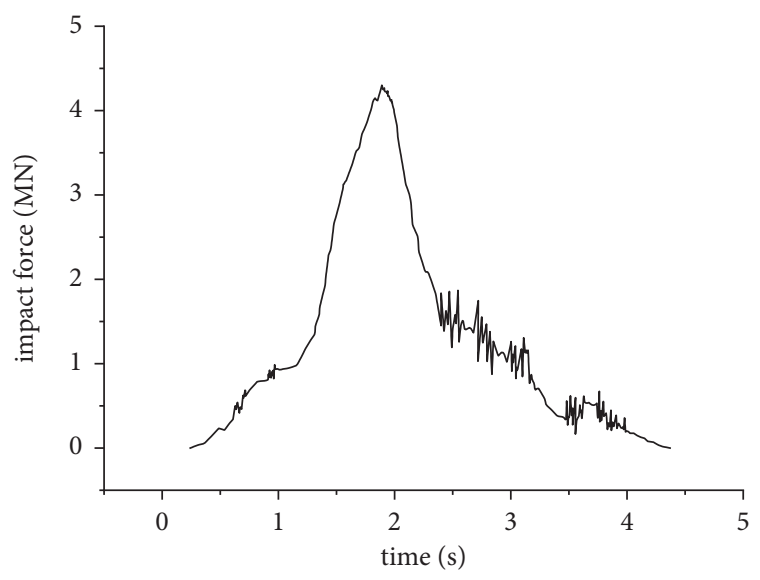

_ Condition 3

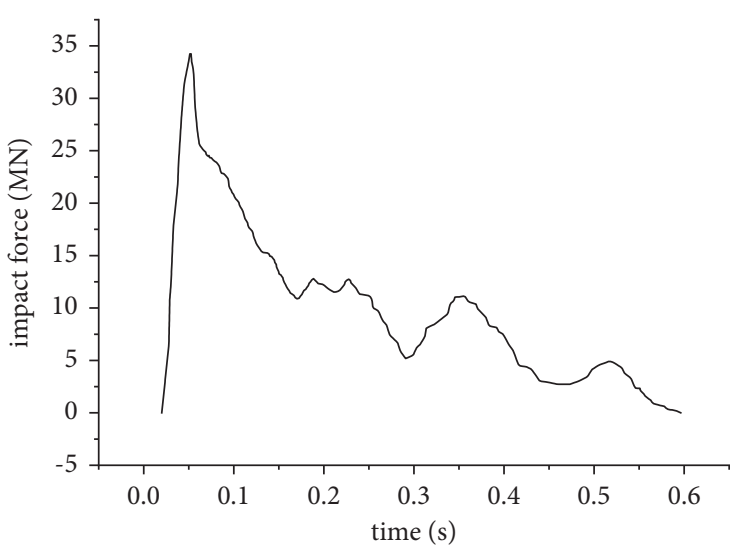

— Condition 4

(b)

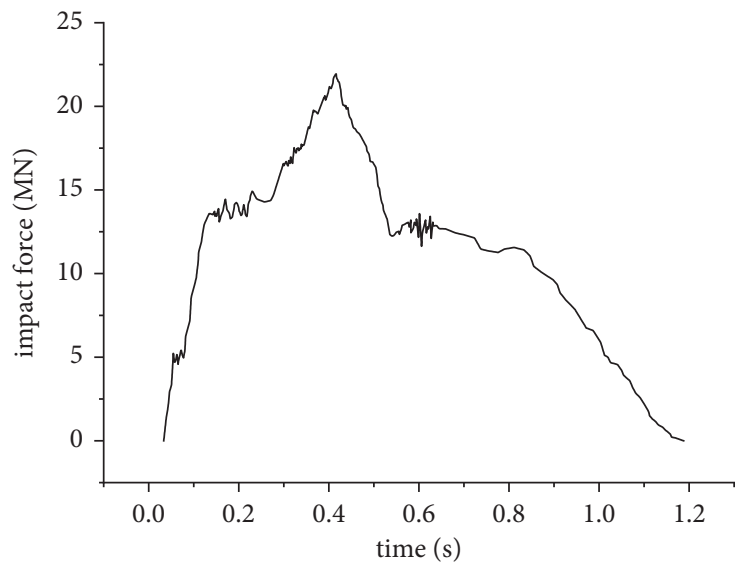

— Condition 5

(d)

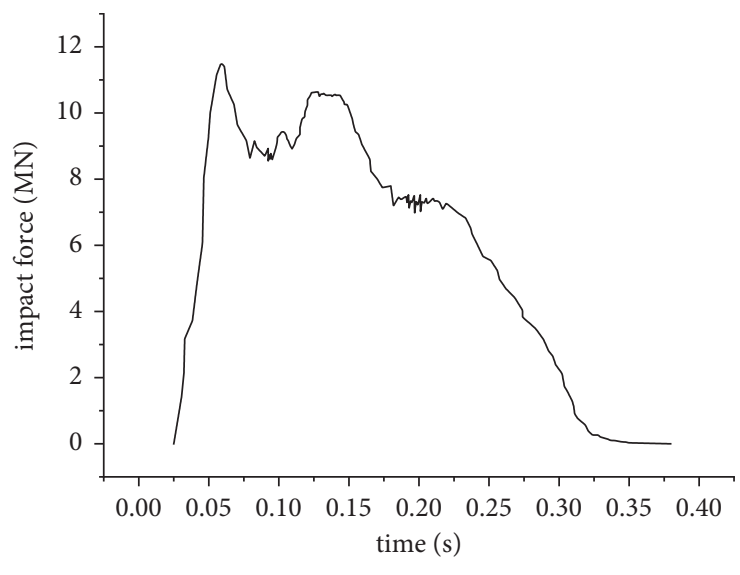

— Condition 6

(e)

(f)

Figure 8: Time of impact force under different conditions. (a) $90^{\circ}$ impact with protective devices under working condition 1 . (b) $90^{\circ}$ impact with protective devices under working condition 4 . (c) $60^{\circ}$ impact with protective devices under working condition 2 . (d) $90^{\circ}$ impact with protective devices under working condition 5 . (e) $30^{\circ}$ impact with protective devices under working condition 3 . (f) $30^{\circ}$ impact with protective devices under working condition 6. 
TABLE 3: Working scenarios of collision of ships of different tonnage.

\begin{tabular}{lcccc}
\hline Conditions & Impact angle $\left(^{\circ}\right)$ & Impact velocity $(\mathrm{m} / \mathrm{s})$ & Tonnage of ship $(\mathrm{t})$ & With anti-collision devices or not \\
\hline 1 & 90 & 3 & 1000 & Yes \\
2 & 90 & 3 & 1500 & Yes \\
3 & 90 & 3 & 2000 & Yes \\
\hline
\end{tabular}

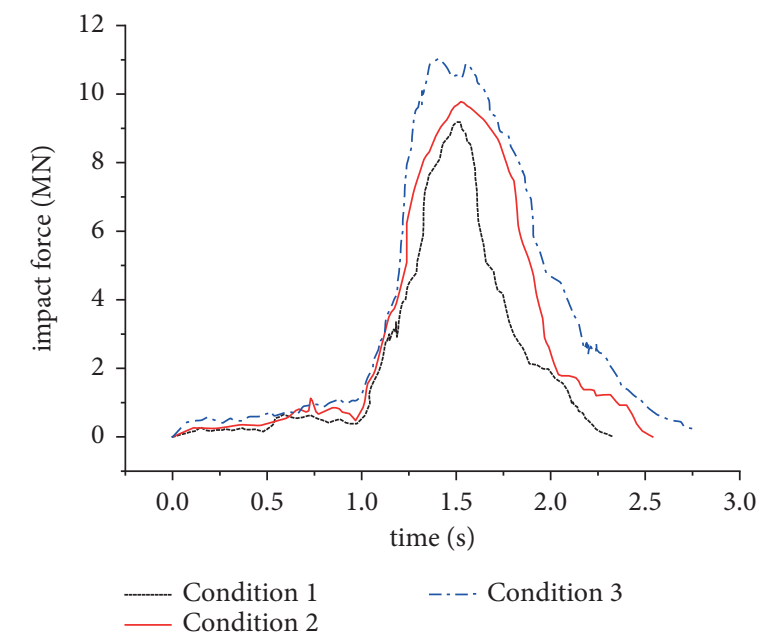

FIGURE 9: Time of impact force of different ship weights on bridge piers with protective devices.

TABLE 4: Working conditions of ship impact at different speeds.

\begin{tabular}{lcccc}
\hline Conditions & Impact angle $\left(^{\circ}\right)$ & Impact velocity $(\mathrm{m} / \mathrm{s})$ & Tonnage of ship $(\mathrm{t})$ & With anti-collision devices or not \\
\hline 1 & 90 & 3 & 1500 & Yes \\
2 & 90 & 4 & 1500 & Yes \\
3 & 90 & 5 & 1500 & Yes \\
\hline
\end{tabular}

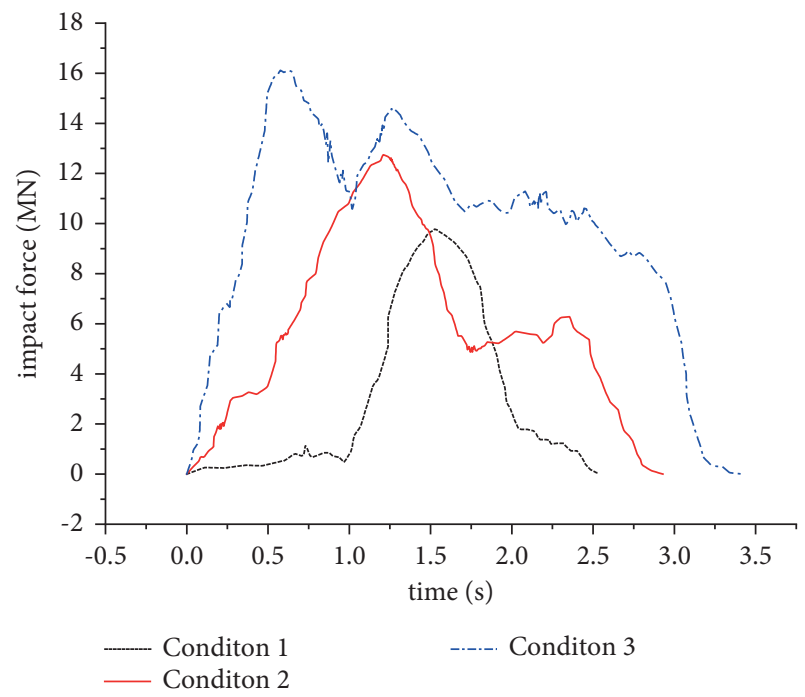

FIGURE 10: Time of collision force when ships at different speeds collide with piers with protective devices.

(2) Using BIM technology, key model control elements can be associated with parameters that can be dynamically adjusted, so as to achieve the goal of visual

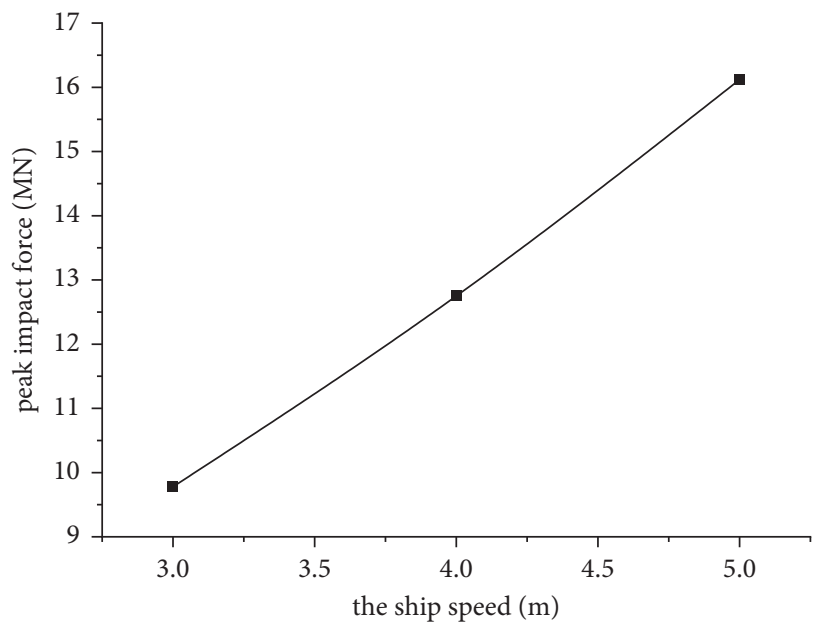

FIGURE 11: Relationship between peak impact force and ship speed at different impact velocities.

parameter adjustment, that is, to complete the automatic update of the adjustment parameter model.

(3) Adjusting the position and angle of the model under different working conditions will not affect the already divided grid. For example, the height of the 

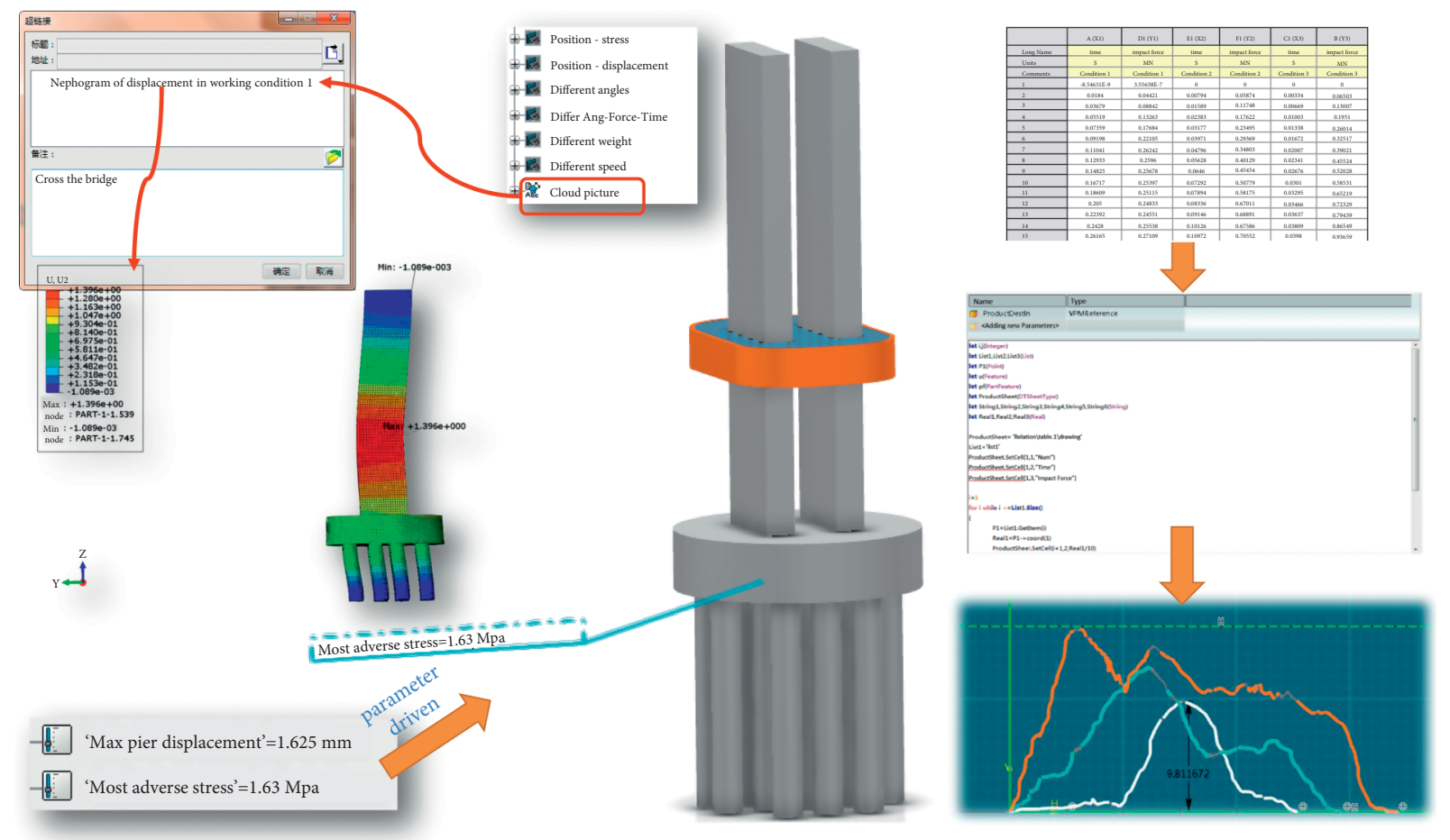

FIgURE 12: Visualization diagram of calculation data based on BIM model.

TABLE 5: Working conditions of calculating for wind tower.

\begin{tabular}{lcccc}
\hline Conditions & Impact angle & Impact velocity $(\mathrm{m} / \mathrm{s})$ & Tonnage of ship $(\mathrm{t})$ & With anti-collision devices or not \\
\hline 1 & $90^{\circ}$ & 1 & 2000 & Yes \\
2 & $90^{\circ}$ & 2 & 2000 & Yes \\
3 & $90^{\circ}$ & 3 & 2000 & Yes \\
4 & $90^{\circ}$ & 1 & 2000 & No \\
5 & $90^{\circ}$ & 2 & 2000 & No \\
6 & $90^{\circ}$ & 3 & 2000 & No \\
\hline
\end{tabular}

TABLE 6: Comparison table for calculating example.

\begin{tabular}{|c|c|c|c|c|c|c|}
\hline \multirow{2}{*}{ Conditions } & \multicolumn{2}{|c|}{ Literature [22] } & \multicolumn{2}{|c|}{ This study } & \multicolumn{2}{|c|}{$\begin{array}{c}\text { Deviation between the literature and this } \\
\text { study }\end{array}$} \\
\hline & $\begin{array}{l}\text { Maximum impact } \\
\text { force }(\mathrm{MN})\end{array}$ & $\begin{array}{c}\text { Time of } \\
\text { occurrence }(s)\end{array}$ & $\begin{array}{l}\text { Maximum impact } \\
\text { force (MN) }\end{array}$ & $\begin{array}{c}\text { Time of } \\
\text { occurrence }(\mathrm{s})\end{array}$ & $\begin{array}{l}\text { Deviation of maximum } \\
\text { impact force }(\%)\end{array}$ & $\begin{array}{l}\text { Deviation of } \\
\text { time }(\%)\end{array}$ \\
\hline 1 & 4.072 & 0.901 & 4.252 & 0.931 & 4.42 & 3.33 \\
\hline 2 & 7.234 & 0.899 & 7.462 & 0.909 & 3.15 & 1.11 \\
\hline 3 & 9.888 & 0.868 & 10.289 & 0.866 & 4.06 & -0.23 \\
\hline 4 & 7.453 & 0.875 & 7.667 & 0.899 & 2.87 & 2.74 \\
\hline 5 & 13.112 & 0.648 & 13.667 & 0.652 & 4.23 & 0.62 \\
\hline 6 & 15.813 & 0.589 & 16.559 & 0.561 & 4.72 & -4.75 \\
\hline
\end{tabular}

pontoon relative to the top of the pier and the angle of the ship are just changing the position of the corresponding model. After adjusting the parameters of the BIM model, the position of the model in the ABAQUS will be updated accordingly, which will not affect the divided grid, boundary, and load condition.

\section{Verification by Calculating Example}

In order to prove the reliability of the safety evaluation results for the pier under the anticollision pontoon protection, the protection structure of rubber-steel plate combination was adopted in literature [22] by calculating example. This study with reference to the constitutive model 
of steel and rubber provided in literature [22] established the BIM model of wind turbine tower and protection device. The key parameters such as ship weight and ship speed are parameterized to realize the transfer of material attributes and key parameters to the finite element model.

A $2000 \mathrm{t}$ ship was simulated to directly impact the wind turbine tower at the speed of $1 \mathrm{~m} / \mathrm{s}, 2 \mathrm{~m} / \mathrm{s}$, and $3 \mathrm{~m} / \mathrm{s} \mathrm{re-}$ spectively, and the response of the wind turbine tower with or without protective devices was calculated. The calculation conditions were shown in Table 5.

The comparison of the calculation examples is shown in Table 6 . The time-history curve is basically consistent with the calculation examples under the calculation conditions, in which the maximum deviation of the impact force and the maximum deviation of the occurrence time are $4.72 \%$ and $-4.75 \%$ respectively. Considering the calculation deviation of different finite element software and the influence of model mesh division on the calculation results, the deviation of the calculated results is within a reasonable range. In conclusion, the results of the calculation method and simulation method in this study are reliable.

\section{Conclusion}

(1) Through the interface between BIM modeling software and finite element analysis software, the oneway linkage between BIM model and finite element model is realized. For the finite element calculation results, the BIM model is associated with parameterized table, time-history curve reconstruction, visual annotation, hyperlink, and other forms through EKL language, so as to realize that the linkage between the BIM model and the calculation results is under different working conditions.

(2) The nonlinear spring simulates the impact of ship damping and incidental water quality in the collision area and determines the most unfavorable response position and change trend of the pier under the protection of the anti-collision pontoon under different water levels. It can be used as a reference when checking the most unfavorable position of similar protective piers.

(3) By considering various working conditions of different angles, different tonnages, and different impact speeds, the safety assessment and analysis of the ship collision pier under the protection of the anticollision pontoon are carried out. The results show that the anti-collision pontoon effectively reduces the hazard of ship collision to the bridge piers, and the impact force gradually increases with the change from oblique collision to forward collision. The maximum impact force increases with the weight of the ship, but it is not linear. The peak value of the impact force increases with the increase of the speed, and the relationship between the speed and the peak value of the impact force is basically linear.

(4) In this study, BIM parameterization technology and object-oriented EKL high-level language method are used to realize the function of visual dynamic adjustment of finite element analysis and improve the efficiency of multi-condition sensitivity analysis. The shortcoming is that the real-time feedback of dynamic calculation results cannot be realized at present. The linkage method of dynamic response process and multi-condition coupling with BIM model is the focus of the next stage of research.

\section{Data Availability}

The data used to support the findings of this study were supplied by the corresponding author under license and so cannot be made freely available. Requests for access to these data should be made to corresponding author.

\section{Conflicts of Interest}

The authors declare that they have no conflicts of interest.

\section{References}

[1] B. Geng, J.-J. Wang, H. Wang et al., "Risk assessment system for bridges against vessel impacts," China Civil Engineering Journal, vol. 40, no. 5, pp. 34-40, 2007.

[2] M. Pregnolato, V. Sarhosis, and C. Kilsby, "Towards integrating modelling of floodinduced bridge failures," $E P i C$ Series in Engineering 13th International Conference on Hydroinformatics, vol. 3, pp. 1698-1702, 2018.

[3] R. Rajendran, Bridge Failures Case Studies in India, Politecnico Milano, Milan, 2019.

[4] C. Putcha, S. Dutta, and J. Rodriguez, "Risk priority number for bridge failures," American Society of Civil Engineers, vol. 25, no. 2, Article ID 04020010, 2020.

[5] R. Allan Leishear, "Bridge safety dangers - fatigue cracks, brittle failures and grit blasting," Journal of Civil, Construction and Environmental Engineering, vol. 6, no. 2, pp. 28-45, 2021.

[6] K.-K. Peng, "Dynamic vessel-bridge collision risk assessment method based on modified AASHTO model," Highway Engineer, vol. 43, no. 2, pp. 12-16, 2018.

[7] S. Ehlers, K. Tabri, J. Romanoff, and P. Varsta, "Numerical and experimental investigation on the collision resistance of the X-core structure," Ships and Offshore Structures, vol. 7, no. 1, pp. 21-29, 2012.

[8] The Performance Study of New Anti Ship Collision Device Ofr Bridge Pier, Chongqing Jiaotong University, Chongqing, 2013.

[9] F Hai-qing, "On the performance of anti-collision steel box for large-span bridge and collision process analysis," Chinese Quarterly of Mechanics, vol. 39, no. 4, pp. 859-865, 2018.

[10] K. Yu, C Xue-quan, C. Tao et al., "Arch self-floating lifting water upper anti-collision device collision avoidance belt structure form comparison and selection," Science Technology and Engineering, vol. 17, no. 13, pp. 66-69, 2017.

[11] B. Geng, L. I. Song-lin, and Z. Zheng, "Research on simplified dynamic analysis method of attached anti-ship collision facilities based on system stiffness," Technology of Highway and Transport, vol. 34, no. 2, pp. 23-25, 2018.

[12] M. A. Xi-qin, K. Yu, L. I. U. Yang et al., "Study of model experiments and numerical simulation of collision between ship and arch anti-collision facility," Journal of Ship Mechanics, vol. 22, no. 2, pp. 206-213, 2018.

[13] L. I. U. Hai-zheng, L. I. Rui, and X. U. Zheng, "Research on anti-collision ability of bridge pier with aluminum foam 
outsourcing concrete," Highway Engineer, vol. 44, no. 4, pp. 13-17, 2019.

[14] D.-B. Jiang and S.-S. Wei, "Study on the fortification criteria of vessel collision and scheme design of protection facility for zengjiayan bridge," Technology of Highway and Transport, vol. 35, no. 3, pp. 53-59, 2019.

[15] R. Fletcher, "An ideal penalty function for constrained optimization," IMA Journal of Applied Mathematics, vol. 15, no. 3, pp. 319-342, 1975.

[16] V. T. B. Quyen, D. N. Tien, and N. N. Dung, "A modified penalty function method for treating multi freedom constraints in finite element analysis of frames," Journal of Physics: Conference Series, vol. 1425, no. 1, Article ID 012097, 2020.

[17] F. Zheng, X. Zhuang, H. Zheng, Y.-Y. Jiao, and T. Rabczuk, "Kinetic analysis of polyhedral block system using an improved potential-based penalty function approach for explicit discontinuous deformation analysis," Applied Mathematical Modelling, vol. 82, pp. 314-335, 2020.

[18] W.-J. Liang, Y.-L. Jin, and G.-Z. Chen, "Calculation of collision force between ship and bridge pier and bridge pier anticollision," Collection of Academic Exchange Papers of China Highway Society, vol. 2001, pp. 346-352, 2001.

[19] W. U. Xiao-ping, "Direct calculation of wave load based on slice theory," Shanghai Shipbuilding, vol. 5, no. 4, pp. 21-25, 2010.

[20] H. M. Lankarani and P. E. Nikravesh, "Continuous contact force models for impact analysis in multi-body system," Nonlinear Dynamics, no. 5, pp. 193-207, 1994.

[21] L. I. Jiang and L. I. Chun, "Spherical collision simulation based on nonlinear spring damping model," Heilongjiang Science, vol. 10, no. 10, pp. 10-13, 2019.

[22] Z.-W. Han, H.-J. Zhou, L. Chun et al., "Dynamic response and anti collision devices of an offshore wind turbine subjected to ship impacts," China Mechanical Engineering, vol. 30, no. 12, pp. 1387-1394, 2019. 